\title{
Review of Desiccant in the Drying and Air-Conditioning Application
}

\author{
Muhammad Safwan Asyraf Ramli ${ }^{1}$, Suhaimi Misha ${ }^{1,2^{*}}$, Nor Faizah Haminudin ${ }^{1}$, Mohd Afzanizam Mohd Rosli ${ }^{1,2}$, \\ Ahmad Anas Yusof ${ }^{1,2}$, Mohd Farriz Md Basar ${ }^{1}$, Kamaruzzaman Sopian $^{3}$, Adnan Ibrahim ${ }^{3}$, Ahmad Fazlizan Abdullah $^{3}$ \\ ${ }^{1}$ Fakulti Kejuruteraan Mekanikal, Universiti Teknikal Malaysia Melaka, Hang Tuah Jaya, 76100 Durian Tunggal, Melaka, \\ Malaysia \\ ${ }^{2}$ Centre of Advanced Research on Energy, Universiti Teknikal Malaysia Melaka, Hang Tuah Jaya, 76100 Durian Tunggal, \\ Melaka, Malaysia \\ ${ }^{3}$ Solar Energy Research Institute, Universiti Kebangsaan Malaysia, 43600 Bangi, Selangor, Malaysia
}

Corresponding Author Email: suhaimimisha@utem.edu.my

https://doi.org/10.18280/ijht.390509

Received: 3 October 2021

Accepted: 29 October 2021

\section{Keywords:}

desiccant, drying, air-conditioning, solid desiccant material, liquid desiccant material, regeneration of desiccant

\begin{abstract}
Desiccant is a hygroscopic substance generally used in the dryer and air-conditioning system as a drying agent. The function of desiccant is to remove moisture from the air to reduce the humidity of the surrounding air been conditioned. This paper presents several works on the performance of desiccant material in the drying and air-conditioning application. It puts focus on the various advantages and disadvantages of the use of desiccant as a drying agent. There are some advantages of using desiccant include consistent drying and low energy usage. However, there are several disadvantages of using desiccants which are low capacity for moisture absorption and pressure drop in solid desiccant. Solar drying applications have some advantages such as being comparatively cheaper than other methods and less risk of spoiling the product. On the contrary, drying applications have disadvantages include being lower in comparison to the original foodstuff and drying foods eventually leads to shrinkage. The advantages of using desiccant in air-conditioning applications offer dehumidified fresh air to keep the building's temperature in a comfortable range and enhances water recovery efficiency. There are disadvantages such as desiccant will substantially impact the system's performance and desiccant should be cooled after completely dried.
\end{abstract}

\section{INTRODUCTION}

The transfer of heat and mass to remove water or other solvents is known as the drying process. Moisture, solid, semisolid, or liquid can be removed from the products by an applied air stream. Nearly 12 per cent of the energy used worldwide is from the drying process [1]. The use of desiccant is one of the drying methods that is utilised. Solid desiccant material absorbs the water by using chemical absorption material. Silica gel, molecular sieve, natural zeolite, activated alumina, and synthetic polymers are examples of solid desiccants. Liquid desiccant is more efficient and sounder in controlling indoor air humidity. The usual liquid used for liquid desiccant is lithium chloride $(\mathrm{LiCl})$, calcium chloride $\left(\mathrm{CaCl}_{2}\right)$ and lithium bromide $(\mathrm{LiBr})$.

The drying temperature is the most crucial parameter for drying rate as such that an increase in the drying temperature will increase the drying rate. Melting or damaging the products are the two drawbacks of a high drying temperature. Furthermore, the additives will separate from the granules and react with the air when the drying temperature is too hot. The flow rate or velocity of air will affect the moisture from the product to evaporate or dissipate. An increase in the velocity of air will also lead to an increase in the drying rate. The excessive usage of high air velocity would increase the cost of the process, and the material used will affect the drying rate based on the moisture in the material. It will eventually damage the product if the process goes on for an extended period. Lastly, humidity refers to the dryness of the air, where the higher the humidity, the lower the drying rate. The energy consumption increases as well when the humidity is too low; as a result, the use of desiccant materials is recommended to control the humidity.

Air-conditioning is a system that cools the area by moving heat outside the designated or desired area [2]. Airconditioning gathers hot air from a room and cools it down with the influence of series of coils and refrigerants. In return, it delivers cooler air to the designated surrounding or the area that it is conditioning. A desiccant is a material that can remove moisture from the air while also dehumidifying it. After becoming saturated with moisture, the desiccant is regenerated to be dried sufficiently to adsorb water vapour in the next cycle. The desiccant substance is heated to do this. The desiccant's type determines the temperature of regeneration.

This paper presents the applications of desiccant material in drying and air-conditioning system. The performance of the systems will be discussed as a guideline in designing the integrated desiccant material with dryer or air-conditioning system in the future. 


\section{SOLID DESICCANT DRYING SYSTEM}

A newly constructed Scheffler reflector with a focus that can be fixed to regenerate the desiccant materials by using three different types of products: activated alumina, molecular sieve, and silica gel [3]. Figure 1 and 2 shows the graph for maximum regeneration rate, maximum absorption rate and average efficiency for different solid desiccant product. Silica gel has the highest result compared to molecular sieve and activated alumina, while the speed of water output can be increased by raising the bed temperature.

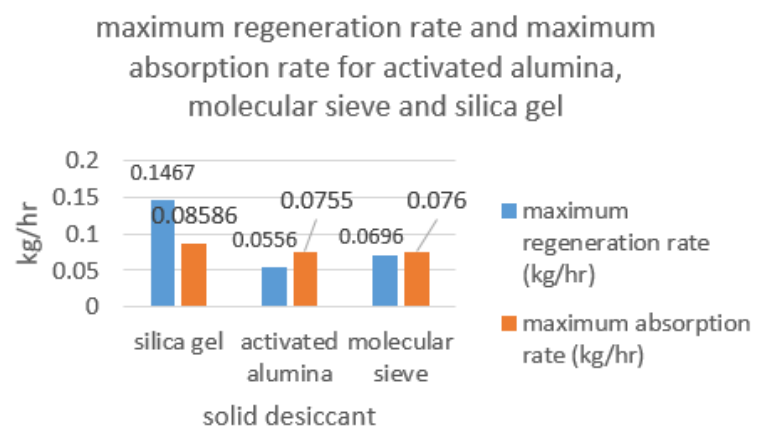

Figure 1. Maximum regeneration rate and maximum absorption rate for different solid desiccant

\section{Average efficiency for activated alumina, molecular sieve and silica gel}

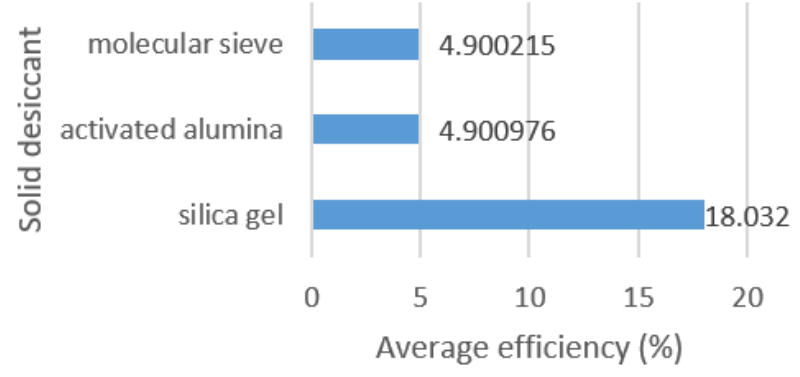

Figure 2. Average efficiency for different solid desiccant

Regeneration has been studied using a Scheffler solar concentrator that included various desiccants made of saturated solid and a new composite desiccant [4]. Moisture content (dry basis) of silica gel is 0.2944 , followed by 0.2205 , 0.19 , and 0.0671 for molecular sieve, novel composite, and activated alumina, respectively. In novel composite, the maximum regeneration rate (mrr) is $0.07440 \mathrm{~kg} / \mathrm{hr}$, and in silica gel, the maximum weight loss percentage is 22.74 per cent. The desiccant regeneration times of silica gel, activated alumina, molecular sieve, and novel composite are 160, 90, 140, and 110 minutes respectively. The solar intensity and wind velocity affect the surface temperature and influence desiccant regeneration by direct heat produced by a Scheffler solar concentrator. Of all the desiccants studied, silica gel has the highest adsorption potential. Figure 3 shows schematic diagram for Scheffler solar concentration that consists several parts which are polar axis, seasonal tracking mechanism, daily tracking mechanism, crossbar, Scheffler concentrator, weighing machine, base and receiver.

Compared to Electro-osmotic Flow (EOF) formed in macro-porous silica gel and activated alumina, EOF formed in zeolite was more stable and less susceptible to all impact factors [5]. However, the macroporous silica gel was highly deformable at various saturation levels and extremely sensitive to joule heat. Therefore, zeolite-based desiccant-coated heat exchanger's effect on greenhouse dehumidification had developed and studied [6]. The range of cyclic Moisture Removal Capacity (MRC) and Coefficient of Performance (COP) is 2.5-4.0 and 0.18-0.3, respectively, which custombuilt Desiccant-coated Heat Exchanger (DC-HX) can achieve. For the baseline state, the optimum adsorption and regeneration times are 40 and 20 minutes, respectively.

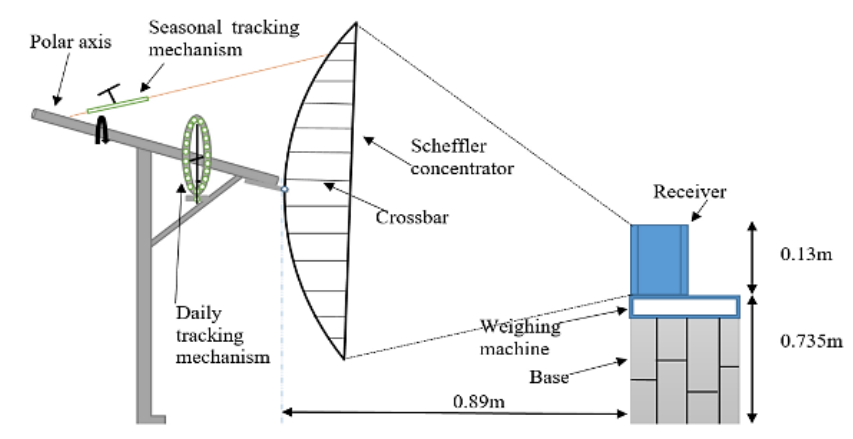

Figure 3. Schematic diagram of Scheffler solar concentration

This research is interested in coatings, dehumidification, energy-saving air-conditioning technologies, and an idea about material synthesis [7]. According to the results, all of the alginate silica gel composites had higher water uptakes than sodium alginate. Furthermore, water adsorption concentrations increased at first, then decreased slightly as the percentage of silica gel in composites increased. The study of Li et al. [8] discusses the output of two stages of Desiccant Coating Heat Exchanger (DCHE) connected in series and coated with silica gel and sodium polyacrylate solid coating desiccants. Results show that at regeneration temperature of $50^{\circ} \mathrm{C}$ and $70^{\circ} \mathrm{C}$, the total dehumidifying capacities of twostage series-connected DCHEs are roughly twice as high as those of a single-stage DCHE. The thermal Coefficient of Performance $\left(C O P_{T H}\right)$ value, dehumidifying capacity, and regeneration capacity of single-stage or two-stage DCHEs increase as the regeneration water temperature rises. Figure 4 and 5 shows schematic diagram for single and two stage of DCHE, respectively.

Bentonite clay and calcium chloride materials were used to make a low-cost solid desiccant [9]. Desiccant can be regenerated at $45^{\circ} \mathrm{C}$ and has a moisture sorption capacity of 45 per cent (dwb). Within 24 hours, the prototype dryer could dry $90 \mathrm{~kg}$ of fresh maise from 38 per cent (dwb) to 15 per cent (dwb). DCHE sorption, desorption volume, and $C O P_{T H}$ are measured at $945.1 \mathrm{~g}, 1115.1 \mathrm{~g}$, and 0.39 , respectively, with processed air inflow temperature, relative humidity, and regeneration temperature set at $30^{\circ} \mathrm{C}, 80$ per cent relative humidity $(\mathrm{RH})$, and $70^{\circ} \mathrm{C}$, respectively [10]. In this case, the processed air inflow temperature and relative humidity are depending on the ambient air condition. The use of hot water in the heat exchanger was able to produce hot air temperature at $70^{\circ} \mathrm{C}$ for regeneration of desiccant material which is much higher than minimum temperature $\left(45^{\circ} \mathrm{C}\right)$ to obtain better regeneration effectiveness. Modulating the cyclic switching time for dehumidification and regeneration processes could improve the DCHE's efficiency. The total $C O P_{T H}$ can be increased over the same period as the rise in cyclic switching time; however, the desiccant's water vapour sorption and desorption quantities were decreased. 


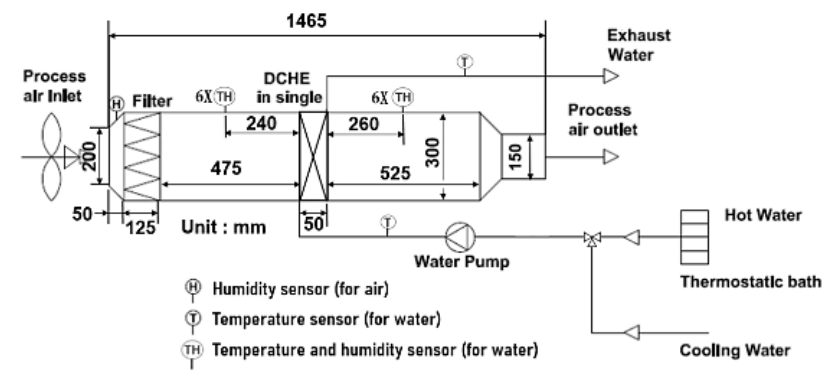

Figure 4. Schematic diagram for single stage Desiccant Coating Heat Exchanger (DCHE)

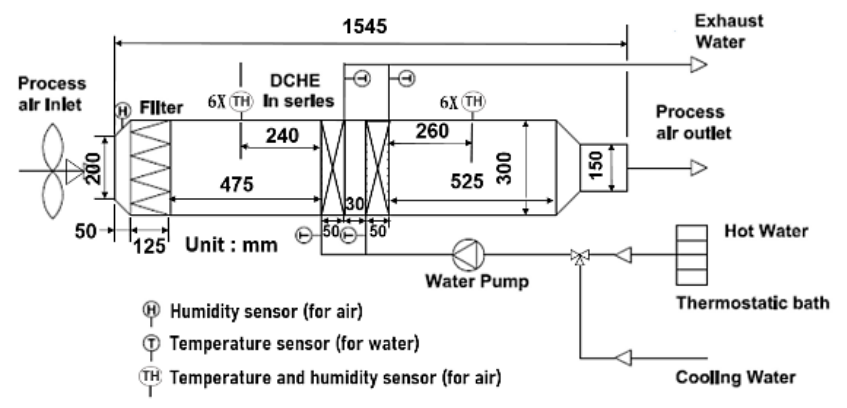

Figure 5. Schematic diagram for two stage Desiccant Coating Heat Exchanger (DCHE)

Mathematical modelling was used to get results for the regeneration of solid desiccant using a solar parabolic dish concentrator [11]. The system's output is unaffected by the amount of oil flowing through it. Higher values of the regeneration rate can be achieved when operational or even geometrical parameters of the device are optimised. The regeneration rate rises up to 17.25 per cent when the inlet airflow to the device increases from $0.05 \mathrm{~kg} / \mathrm{s}$ to $0.15 \mathrm{~kg} / \mathrm{s}$, and it decreases up to 52 per cent when the $\mathrm{RH}$ of the inlet air increases from 10 to 50 per cent. The regeneration rate is increased by up to 40 per cent by increasing the inlet air temperature from $25^{\circ} \mathrm{C}$ to $45^{\circ} \mathrm{C}$.

The developed Gaussian Process Regression (GPR) model serves as a quick and accurate predictive tool for the design of dehumidification systems as well as the commercialisation of the investigated dehumidification systems [12]. The maximum Root Mean Square Error (RSME) and Mean Absolute Percentage Error (MAPE) for moisture extraction are just 0.045 and 0.21 per cent, respectively, while moisture removal efficiencies are 0.082 and 0.39 per cent, with an R2 value of 0.97 .

Computer modelling was used to compare the efficiency of desiccant wheels made of RD silica gel (SG), AQSOA-Z02, and CECA-3A [13]. While based on adsorption isotherms, the AQSOA-Z02 was shown to have a higher dehumidification capability. It was also discovered that the desiccant wheel using SG would have better overall efficiency due to its lower heat of adsorption. However, in comparison to AQSOA-Z02, silica gel performed better in both fresh air (FF) and return/exhaust air (FR) modes. AQSOA-Z02 has the potential to outperform silica gel under the conditions of lower ambient temperature and relative humidity and a higher regeneration temperature at a low wheel speed. The dehumidification efficiency of a desiccant wheel using CECA-3A was found to be the worst comparatively.

The concept of recovering heat from an integrated heat pump's condenser was studied [14]. In this case, a solarassisted hybrid solid desiccant cooling system (SDCS) was developed, in which solar-heated water is used as an additional heat source for the regeneration process. The performance of the device enhances with a high outdoor humidity ratio. The systems' COP steadily increases as the ambient temperature rises. However, when the ambient temperature exceeds the critical value, the COP slowly decreases even with an increase in the ambient temperature, which is unusual of the standard nature. Changes in ambient circumstances have a significant impact on SDCS performance. The optimum outdoor temperature for hybrid SDCS is $26-27^{\circ} \mathrm{C}$, whereas the optimum outdoor temperature for solar-assisted hybrid SDCS is $27-30^{\circ} \mathrm{C}$. Beyond the ranges, both systems' overall performance will decrease dramatically. Higher humidity ratios result in better Moisture Removal Rate (MRR) values for each solid desiccant cooling system configuration.

Performance output predicted by the Artificial Neural Network (ANN) model has a high correlation factor of $\mathrm{R}>0.98336$ [15]. The results predicted by the ANN model demonstrate that the model can be used to predict the performance of a solid desiccant wheel accurately and reliably. For temperature and relative humidity, the maximum percentage difference between the experimental and ANN model results is 8 per cent and 15 per cent, respectively. The model's accuracy is determined by the number of hidden layers in the model and the amount of data used to train the network.

Analysis of Systems (ANSYS) fluent fluid flow systems in ANSYS Workbench are used for computational fluid dynamic analysis [16]. The temperature and velocity distributions for three different revolutions per minute (RPMs) were determined using simulation results. The highest recovery rate could be achieved for the experiments by adjusting the following parameters: heat input, drum rotating RPM, and liquid spray rate. At $1.18 \mathrm{RPM}$ and $22 \mathrm{ml} / \mathrm{min}$, the maximum recovery rate of $433.3 \mathrm{~g} / \mathrm{h}$ was achieved. Increase the thickness of the insulation to enhance the construction. There should be good optimisation between cylinder RPM and liquid spray pulse rate to achieve the best recovery rate.

The regeneration process for solid and liquid desiccants was reviewed [17]. Various researchers have proposed numerous techniques to reduce the expense of the regeneration process. The majority of techniques use solar energy for the reactivation process because it is both inexpensive and environmentally friendly. Hot air is used to regenerate the desiccant wheel and raise the temperature of the drying air after dehumidification [18]. Open sun drying time for moisture content ranging from 69 per cent to 29 per cent is approximately 30 hours and 40 minutes. For experiments 1,2 , and 3, the percentages for solar energy usage are 65 per cent, 57 per cent, and 79 per cent, respectively. In comparison to open sun drying, solar dryers take approximately 64 per cent, 44 per cent, and 33 per cent drying reduction for the first, second, and third columns, respectively. Since the moisture content of the product and the quantity of the product are reduced in experiments 2 and 3, the drying efficiency and pickup efficiency are reduced. The drying air quality improves with desiccant wheel's latent effectiveness of 67 per cent while sensible effectiveness is 74 per cent.

Compares the results of using a solar dryer versus open sun drying [19]. The drying time was decreased from 20.75 to 15.75 hours to achieve a moisture content of less than 18 per cent. Approximately 12 per cent dryer performance and solar energy account for 44 per cent of total energy consumption. 
The air velocity is more critical than the air temperature and humidity to extract moisture from the surface of the produce at an early stage. When the moisture content of the air is minimal, the air temperature is critical for moving the water from the interior to the surface. The benefits of using a solarassisted dryer include lower humidity (due to desiccant material absorption), higher volume drying capability, improved drying uniformity, the ability to work at low solar radiation, and suitability for a wide range of products.

Reviewed the use of solid/liquid desiccants in drying applications and the methods for regenerating them [1]. A desiccant system offers many benefits in a drying application, including continuous drying even during off-sunshine hours, increased drying rate due to hot and dry air, more uniform drying, and improved product quality, especially for heatsensitive products. In a drying method, using heat to regenerate desiccant material has drawbacks in terms of energy savings. The use of composite desiccant materials may improve the moisture adsorption capacity of the material.

A solar dryer with integrated indirect forced convection was studied and desiccant is designed and built to test its efficiency in hot and humid conditions [20]. The consistency of the drying product increases with solar drying and desiccant unit incorporation during the off-sunshine hours as goods begin to dry. At airflow rates of $0.01 \mathrm{~kg} / \mathrm{m}^{2} \mathrm{~s}, 0.02 \mathrm{~kg} / \mathrm{m}^{2} \mathrm{~s}$, and 0.03 $\mathrm{kg} / \mathrm{m}^{2} \mathrm{~s}$, the commodity dries to the equilibrium moisture content is around 22, 18, and 14 hours, respectively. The system's output is promising, with a pick-up efficiency of 63 per cent at 10.30 a.m. and more or less uniform desiccant drying. The drying was started at 8.00 a.m. at low solar irradiation. After 150 minutes which is at 10.30 a.m. the solar irradiation increases and the highest pickup efficiency value is obtained since at the early stage, drying is relatively easy but at the later stage the pickup efficiency decrease due to decrease in moisture content in the product. Drying and pick-up efficiencies declined as the moisture content of the products decreased and less quantity of product in the drying chamber [18]. The value of pick-up efficiency exceeds $50 \%$ is considered as good drying performance. The rate of the basic moisture extraction ranges between 0.55 and $0.82 \mathrm{~kg} / \mathrm{kW} \mathrm{h}$.

\section{LIQUID DESICCANT DRYING SYSTEM}

Various liquid desiccant regeneration methods are described in this research, including the most advanced form of photovoltaic/electrodialysis regeneration [21]. The most popular liquid desiccant (LD) cooling system is the packed bed. In order to prevent internal cooling and improve efficiency, a high flow rate of liquid desiccant is used. Triethylene Glycol (TEG), Calcium Chloride $\left(\mathrm{CaCl}_{2}\right)$, Lithium Chloride ( $\left.\mathrm{LiCl}\right)$, Pottasium Formate $\left(\mathrm{KCO}_{2} \mathrm{H}\right)$ and Lithium Bromide $(\mathrm{LiBr})$ are some of the most often used liquid desiccants. Table 1 shows liquid desiccant concentration and flow rate. Gelcast alumina bodies were osmotically dried in water solutions containing various polyethylene glycols (PEGs) with molecular weights ranging from 1000 to $80,000 \mathrm{~g} / \mathrm{mol}$ [22]. The effect of the gelcast body size was investigated and associated with the green body structure. Gelcast bodies submerged in a 43 wt per cent solution of PEG 80000 could lose up to 30 per cent of their water content. The dewatering was minimised because smaller PEG molecules entered the gelled bodies. The most effective liquid desiccant was a water solution of polyethylene glycol with the highest molecular weight.
Table 1. Liquid desiccant concentration and flow rate

\begin{tabular}{cccc}
\hline $\begin{array}{c}\text { Liquid } \\
\text { Desiccant }\end{array}$ & $\begin{array}{c}\text { Concentration } \\
(\boldsymbol{\%})\end{array}$ & $\begin{array}{c}\text { Flow Rate } \\
\left(\boldsymbol{m}^{3} / \mathbf{m i n}\right)\end{array}$ & Source \\
\hline $\mathrm{TEG}$ & $93-98 \%$ & $1.5-2.07$ & {$[23]$} \\
$\mathrm{CaCl}$ & $39 \%$ & - & {$[24]$} \\
$\mathrm{LiCl}$ & $35 \%$ & $0.6-0.7$ & {$[25]$} \\
$\mathrm{LiBr}$ & $53-57 \%$ & 3.76 & {$[26]$} \\
$\mathrm{KCO}_{2} \mathrm{H}$ & $62 \%$ & $0.65-0.7$ & {$[27]$} \\
\hline
\end{tabular}

Drying $\mathrm{BaTiO}_{3}$-based semiconducting ceramic gelcast parts that use a liquid desiccant process was focused [28]. According to the findings, the loading amount of ceramic powders and the concentration of liquid desiccant have a major impact on the drying process and the sintering characteristics of ceramic components. As the solid loading of green gelcast parts is increased to over 45 per cent, the stresses that form during drying are significantly reduced, and a higher concentration of liquid desiccant can be used without causing defects in the drying process, resulting in defect-free ceramic with a smooth surface. Higher solid content and a lower component thickness will increase the density of ceramics in the gel. The amount of ceramic powder loaded and the concentration of liquid desiccant have a major impact on the drying process and the sintering characteristics of ceramic pieces.

A two-stage regeneration of the liquid desiccant, an aqueous calcium chloride solution, is used to increase energy efficiency [29]. The novel contacting system, which has 120-185 per cent more surface density than traditional packaging, eliminates liquid desiccant carryover into the process and regenerated air streams. Therefore, compared to traditional hot air drying systems Desiccant-Based Dryer (DBD) is more energy-efficient. Furthermore, since the process air temperature in the dryer is usually below $50^{\circ} \mathrm{C}$, heat-sensitive items may be dried.

Four desiccant dehumidification systems capable of being powered by waste heat Desiccant-style systems (wheel type and batch-type with the only desiccant), a system with a precooled, double-stage-type systems (two desiccant wheels and a four-partition desiccant wheel type), and a batch-type system with an internal heat exchanger are all examples of traditional desiccant-type systems [30]. The lowest heated air temperature (approximately $33^{\circ} \mathrm{C}$ ) will significantly lower the system than the conventional system. The temperature of the hot air may be reduced by lowering the temperature of the cooled air.

Green gelcast ceramic pieces that dried using a liquid desiccant drying system to speed up the drying process and eliminate defects [31]. As liquid desiccants, various amounts of PEG 1000 aqueous solution were used. Higher ceramic loading, lower liquid desiccant solution concentration, and sample thickness reduce the drying rate and lengthen the time it takes for the sample to achieve equilibrium. The engineering model predicts drying rates accurately over a sufficiently wide range of component thicknesses, ceramic loading, and liquid desiccant concentration.

Malformations may be reduced or removed by using the liquid desiccant drying process due to the release of residual stresses [32]. The drying rate can be increased by lowering the solid content in the gel, increasing the liquid desiccant concentration, and decreasing the effective thickness of components. This approach effectively removes all defects that occur during traditional drying while also reducing drying time. Lowering the ceramic loading level, increasing the 
concentration of the liquid desiccant solution, and decreasing the component's effective thickness all help speed up the drying process and shorten the drying time. In cylindrical sections, lowering the aspect ratio increases the drying rate and shifts the diffusion mechanism from radial to longitudinal.

A liquid desiccant-assisted solar dryer to dry tomato slices was used [33]. A liquid dryer provides the required electrical energy and regenerates the desiccant. A photovoltaic-thermal solar collector was employed with lower drying temperatures; both the solar heat fraction and the ratio of solar electricity to used electricity increased. When utilising an activation $\mathrm{RH}$ of 18 per cent instead of 28 per cent, the drying time was reduced by 27 per cent. Increasing the temperature from 60 to $70^{\circ} \mathrm{C}$, a 10 per cent reduction in drying time will occur. At a temperature of $70^{\circ} \mathrm{C}$ and a 28 per cent activation $\mathrm{RH}$, the most prominent electrical energy usage was found. The solar electricity to consumed electricity (SECE) values ranged from 0.45 to 1.7 .

Investigation the performance of separate liquid and solid desiccant dehumidification systems with single-stage and twostage, as well as the performance two-stage combination liquid and solid desiccant dehumidification systems with reference to a humid region [34]. A dehumidification system with a capacity of $25 \mathrm{~kW}$ is constructed for room air-conditioning applications using the thermal models given in the literature. Solid and liquid desiccant materials used are RD-type silica gel and $\mathrm{LiCl}$, respectively. For room air-conditioning, the single-stage solid desiccant dehumidification system (SSDD) and two-stage solid desiccant dehumidification system (TSDD) perform better when the airflow rate and humidity ratio are high and the air inlet temperature is low. Similar results are obtained by the use of a single-stage liquid desiccant dehumidification system (SLDD) and a two-stage liquid desiccant dehumidification system (TLDD), and a two-stage combined liquid and solid desiccant dehumidification system (CLSDD). Therefore, the SSDD, TSDD, SLDD, TLDD, and CLSDD systems perform better in deep drying applications with low airflow rates and high air inlet temperatures.

Experiments examine the drying performance of a unique compressed air drying method employing several liquid desiccants, including $\mathrm{LiCl}$ solution, $\mathrm{LiBr}$ solution, and mixed solutions $\left(\mathrm{LiCl} / \mathrm{CaCl}_{2}\right)$ [35]. $\mathrm{LiCl}$ solution has a more extraordinary drying performance than $\mathrm{LiBr}$ solution, and the drying performance of three mixed solutions ( 44 per cent, 46 per cent, and 49 per cent) selected is comparable to that of a 40 per cent $\mathrm{LiCl}$ solution, indicating that a single solution can be replaced with a significantly cheaper mixed solution. Furthermore, the cost of the three hybrid solutions is at least 18 per cent less than that of a 40 per cent $\mathrm{LiCl}$ solution, showing significant cost savings in the application.

\section{APPLICATION OF DESICCANT IN AIR- CONDITIONING SYSTEM}

Two designs of heat pump-driven liquid desiccant (HPLD) air-conditioning systems were proposed [36]. Out of the two cases, case A has a strong solution with a sump instantly mixing weak solution, and case B has strong solutions with dual sumps containing weak solution. Results show that case B saves energy consumption and improves mean energy efficiency compared to case A with 28 per cent and 37.5 per cent, respectively. In comparison to case A, case B saved 12 per cent of energy and increased mean energy efficiency by
4.95 per cent in the winter operating mode. Without the need for any extra tools, HPLD can act as a multi-functional airconditioning system.

One of the best approaches to assess device output under load variations during the initial design stages is to use modelbased simulation and optimisation [37]. For example, for a standalone absorption device, the optimised solar fraction is 57.50 per cent, and the thermal COP is 0.55 , while for an integrated absorption desiccant system (IADS), the solar fraction is 56.20 per cent, and the thermal COP is 1.52 . Three cities with different climates were analysed using two different sizes of multi-generation systems [38]. In Tehran, Rasht, and Bandar Abbas, the thermal COP of desiccant cooling systems is 1.06, 0.67, and 0.73, respectively. Thus, in Rasht and Bandar Abbas, respectively, the proposed water recovery cycle will compensate 121 per cent and 64 per cent of annual water consumption by an evaporative cooler. Two revolutionary cycles are utilised in the desiccant system, where the humidity of regeneration air is higher than in standard systems. As a result, the dew point temperature will be high enough to allow water condensation to occur. Figure 6 shows the $C O P_{T H}$ for different three cities.

\section{Thermal Coefficient of Performance (COP) for different three cities}

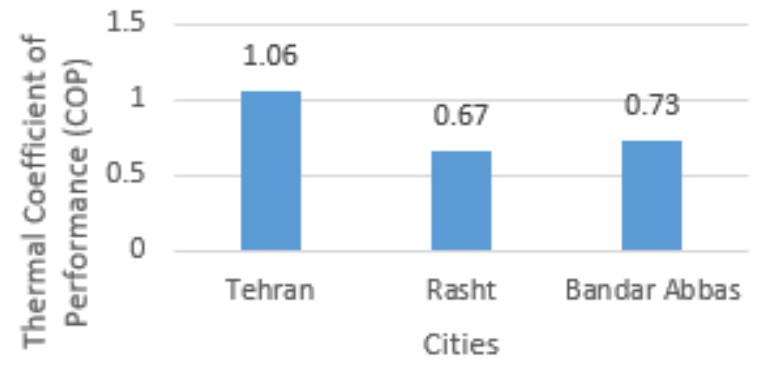

Figure 6. Thermal coefficient of performance (COP) for different three cities

A hybrid photovoltaic-thermal collector-solar air heater (PVT-SAH) was developed and coupled with a building model to evaluate the performance optimisation of the system [39]. The energy efficiency of the desiccant cooling system was evaluated and optimised using the models developed. The electrical COP of optimal designs was higher than that of nonoptimal designs, ranging from 0.6 to 15.1 per cent. In a typical year, the desiccant cooling system and control technique will efficiently control the indoor air conditions in the house, keeping the indoor operative temperature between $22-24.1{ }^{\circ} \mathrm{C}$ and the relative humidity between $35.2-64.8$ per cent.

Experimental bench and a steady-state mathematical model of the entire system created to investigate the system performance [40]. A mathematical model is used to examine the impact of many essential parameters on system performance, such as solution flow rate, solution temperature, and ambient variables. In studies, the average regeneration temperature was $72.9^{\circ} \mathrm{C}$, demonstrating that utilising waste heat from the air compressor to drive solution regeneration is a viable option. In addition, a higher solution flow rate causes a lower inlet solution temperature of the dehumidifier. In contrast, a lower humidity ratio is affected by the higher inlet solution temperature of the regenerator. The temperature of $70^{\circ} \mathrm{C}$ (summer), $39^{\circ} \mathrm{C}$ (winter), and $60^{\circ} \mathrm{C}$ (transitional season) 
are some of the selected regeneration temperatures in various ambient situations.

The compressed air drying system's coupled heat and mass transfer characteristics using liquid desiccant, experimental and theoretical analysis [41]. Increases in air pressure compressed air velocity, and solution concentration could significantly improve heat and mass transfer coefficients between compressed air and solution. Under $0.80 \mathrm{MPa}$, the lowest feasible humidity ratio of exit compressed air is 0.11 $\mathrm{g} / \mathrm{kg}$, and the dew point temperature under atmospheric pressure is around $37.0^{\circ} \mathrm{C}$, indicating that it can fulfil realistic and practical industrial applications' demands. Higher air pressure assists in increasing the mass transfer coefficient (hd) and heat transfer coefficient (hc) between compressed air and the desiccant solution; however, the higher liquid desiccant temperature has a considerable negative impact on coupled heat and mass transfer performance. The higher temperature of liquid desiccant has a negative impact because the adsorption rate of desiccant material decrease when the temperature of the material increase. This is the main reason, sometimes the desiccant material is cool down after the regeneration process to reduce the temperature of desiccant material and improve the adsorption rate.

A counter-flow pressurised dehumidifier loaded with structured packing, investigates the mass transfer performance between compressed air and $\mathrm{LiCl}$ aqueous solution experimentally [42]. Increases in air pressure and liquid desiccant input concentration can significantly improve compressed air drying performance, but the effect of liquid desiccant temperature is negative. The liquid-to-compressedair flow rate ratio is suggested to be kept around 1.5 at a pressure of $0.50 \mathrm{MPa}$ to ensure high compressed air drying performance while lowering air compressor and liquid desiccant pump power consumption.

A desiccant is a material with a high affinity for water that can be used to remove moisture from the air was studied [2]. In hot and humid climates, desiccant air conditioner systems are recommended as an alternate approach for lowering energy usage and greenhouse gas emissions. Desiccant materials can provide hot, dry air that can be used for drying as well as air conditioning to reduce the latent heat load [43]. Solid desiccant is highly porous in nature and adsorb water by using mechanisms of chemical adsorption while liquid desiccant is generally very strong solutions of ionic salts and their behaviour is controlled by changing its temperature and concentration. Water vapour can be eliminated from desiccant via regeneration when exposing to regeneration airstream with temperature from 50 to $250^{\circ} \mathrm{C}$. The usage of composite desiccant material can improve moisture absorption capacity around $200-300 \%$ compare to solid and liquid desiccant. The availability of regenerating heat to regenerate desiccant material is a problem faced by desiccant systems and the system will be more cost effective if solar energy and waste heat are used to regenerate desiccant material.

\section{CONCLUSIONS}

This paper provides an in-depth discussion of the research carried out in reputed academic journals on desiccant material performance for drying and air-conditioning applications. The findings that can be concluded from the previous work are as follows:

1. Some of the advantages of using a desiccant system are: continuous drying even at night or cloudy days, increasing drying rate, consistent drying, improving the quality of the product, particularly for the product that is sensitive to heat, low energy usage, and improving air quality.

2. Meanwhile, some of the drawbacks of using a desiccant system are; a low capacity for moisture absorption, pressure drop in solid desiccant, and liquid desiccant carryover by the airstream. However, the drawbacks are not limited to these only. Few other notable points are; regeneration of the desiccant material when it is saturated, regeneration process for desiccant material, the high initial cost to set up the system, and liquid desiccant could be corrosive and damage the system or components.

3. Temperature, velocity, and humidity of air are the critical properties that can affect the drying rate. High drying temperature, high velocity of the air, and low humidity will produce an efficient drying system. The humidity of air only can be controlled by using desiccant material. However, it required additional energy to regenerate the saturated desiccant. The use of appropriate methods and technology will make the application of desiccant material worth the use.

4. The application of desiccant in air-conditioning system will reduce the latent heat load to produce hot and dry air by extracting the moisture from the air. Others advantages of using desiccant in air-conditioning application are minimize the usage of energy, reduce greenhouse gas emission, increase capability moisture absorption and reduce regeneration temperature.

\section{ACKNOWLEDGMENT}

The authors are grateful to Universiti Teknikal Malaysia Melaka (UTeM) and Universiti Kebangsaan Malaysia (UKM) for sponsoring this work under Grant MRUN/2020/FKMCARE/MR0001 and MRUN-RAKAN RU-2009-001/2.

\section{REFERENCES}

[1] Misha, S., Mat, S., Ruslan, M.H., Sopian, K. (2012). Review of solid/liquid desiccant in the drying applications and its regeneration methods. Renewable and Sustainable Energy Reviews, 16(7): 4686-4707. https://doi.org/10.1016/j.rser.2012.04.041

[2] Ghadamian, H., Salarian, H. (2009). Application of desiccant in modern air conditioning systems. Conference: R09 Twin World Congress (Resource Management and Technology for Material and Energy Efficiency)At: Davos, Switzerland.

[3] Srivastava, S., Yadav, A. (2018). Extraction of water particles from atmospheric air through scheffler reflector using different solid desiccants. International Journal of Ambient Energy, 41(12): 1357-1369. https://doi.org/10.1080/01430750.2018.1517667

[4] Malan, A., Kamboj, V., Sharma, A.K., Yadav, A. (2020). The regeneration of various saturated solid and novel composite desiccant using Scheffler solar concentrator: An experimental investigation. International Journal of Ambient Energy, 41(2): 224-236. https://doi.org/10.1080/01430750.2018.1456965 
[5] Cai, S., Huang, W., Luo, X., Li, X., Ji, J. (2019). Experimental study on the impact factors of electroosmotic flow in dehumidification applications. Energy and Buildings, 202: 109388 https://doi.org/10.1016/j.enbuild.2019.109388

[6] Amani, M., Bahrami, M. (2021). Greenhouse dehumidification by zeolite-based desiccant coated heat exchanger. Applied Thermal Engineering, 183(1): 16178. https://doi.org/10.1016/j.applthermaleng.2020.116178

[7] Zheng, Z., Chen, K., Lin, Z. (2020). Synthesis and characterization of alginate-silica gel composites for absorption dehumidification. Industrial \& Engineering Chemistry Research, 59(13): 5760-5767. https://ds.doi.org/10.1021/acs.icer.9b06157

[8] Li, K.Y., Luo, W.J., Tsai, B.Y., Der Kuan, Y. (2020). Performance analysis of two-stage solid desiccant densely coated heat exchangers. Sustainability (Switzerland), 12(18): 7357. https://doi.org/10.3390/SU12187357

[9] Thoruwa, T.F.N., Smith, J.E., Grant, A.D., Johnstone, C.M. (1996). Developments in solar drying using forced ventilation and solar regenerated desiccant materials. Renewable Energy, 9(1-4): 686-689. https://doi.org/10.1016/0960-1481(96)88378-9

[10] Panigrahi, B., Chen, Y.S., Luo, W.J., Wang, H.W. (2020). Dehumidification effect of polymeric superabsorbent SAP-LiCl composite desiccant-coated heat exchanger with different cyclic switching time. Sustainability (Switzerland), 12(22): 1-16 https://doi.org/10.3390/su12229673

[11] Avargani, V.M., Karimi, R., Gheinani, T.T. (2019). Mathematical modeling of an integrated system for regeneration of solid desiccants using a solar parabolic dish concentrator. International Journal of Heat and Mass Transfer, 142: 118479. https://doi.org/10.1016/j.ijheatmasstransfer.2019.11847 9

[12] Akhlaghi, Y.G., Zhao, X., Shittu, S., Badiei, A., Cattaneo, M.E.G.V., Ma, X. (2019). Statistical investigation of a dehumidification system performance using Gaussian process regression. Energy and Buildings, 202: 109406. https://doi.org/10.1016/j.enbuild.2019.109406

[13] Fong,K.F., Lee, C.K. (2018). Impact of adsorbent characteristics on performance of solid desiccant wheel. Energy, 144 1003-1012. https://doi.org/10.1016/j.energy.2017.12.113

[14] Luo, W.J., Faridah, D., Fasya, F.R., Chen, Y.S., Mulki, F.H., Adilah, U.N. (2019). Performance enhancement of hybrid solid desiccant cooling systems by integrating solar water collectors in Taiwan. Energies, 12(18): 1-18. https://doi.org/10.3390/en12183470

[15] Mishra, V.K., Singh, R.P., Das, R.K. (2018). Performance prediction of solid desiccant rotary system using artificial neural network. IOP Conference Series: Materials Science and Engineering, 404(1): 012006. https://doi.org/10.1088/1757-899X/404/1/012006

[16] Kaviska Yapa, Y.M.C.L., Saliya Jayasekara, J.G.A (2020). Design modelling and the performance analysis of a recycling drum dryer for a salt adsorbent. 2020 6th International Conference on Control, Automation and Robotics, ICCAR 2020, pp. 335-341. https://doi.org/10.1109/ICCAR49639.2020.9107992

[17] Mahanta, D.K., Sarma, B. (2017). Regeneration of solid and liquid desiccant: A review. IEEE International
Conference on Power, Control, Signals and Instrumentation Engineering, pp. 614-619. https://doi.org/10.1109/ICPCSI.2017.8391786

[18] Misha, S., Sohif, M., Ruslan, M.H., Salleh, E., Sopian, K.B. (2016). Performance of a solar-assisted solid desiccant dryer for oil palm fronds drying. Solar Energy, 132: 415-429. https://doi.org/10.1016/j.solener.2016.03.041

[19] Misha, S., Mat, S., Ruslan, M.H., Salleh, E., Sopian, K. (2015). Performance of a solar assisted solid desiccant dryer for kenaf core fiber drying under low solar radiation. Solar Energy, 112: 194-204. https://doi.org/10.1016/j.solener.2014.11.029

[20] Shanmugam, V., Natarajan, E. (2006). Experimental investigation of forced convection and desiccant integrated solar dryer. Renewable Energy, 31(8): 12391251. https://doi.org/10.1016/j.renene.2005.05.019

[21] Salikandi, M., Ranjbar, B., Shirkhan, E., Shanmuga Priya, S., Thirunavukkarasu, I., Sudhakar, K. (2021). Recent trends in liquid desiccant materials and cooling systems: Application, performance and regeneration characteristics. Journal of Building Engineering, 33: 101579. https://doi.org/10.1016/j.jobe.2020.101579

[22] Trunec, M.. (2011). Osmotic drying of gelcast bodies in liquid desiccant. Journal of the European Ceramic Society, 31(14): 2519-2524. https://doi.org/10.1016/j.jeurceramsoc.2011.02.015

[23] Zurigat, Y.H., Abu-Arabi, M.K., Abdul-Wahab, S.A. (2004). Air dehumidification by triethylene glycol desiccant in a packed column. Energy Conversion and Management, 45(1): 141-155. https://doi.org/10.1016/S0196-8904(03)00109-2

[24] Bai, H., Zhu, J., Chen, Z., Ma, L., Wang, R., Li, T. (2017) Performance testing of a cross-flow membrane-based liquid desiccant dehumidification system. Applied Thermal Engineering, 119: 119-131. https://doi.org/10.1016/j.applthermaleng.2017.03.058

[25] Mago, P., Goswami, D.Y. (2003). A study of the performance of a hybrid of a hybrid liquid desiccant cooling system using lithium chloride. Journal of Solar Energy Engineering, 125(1): 129-131. https://doi.org/10.1115/1.1530199

[26] Lazzarin, R.M., Gasparella, A., Longo, G.A. (1999). Chemical dehumidification by liquid desiccants: Theory and experiment. International Journal of Refrigeration, 22(4): $\quad 334-347 . \quad$ https://doi.org/10.1016/S01407007(98)00044-9

[27] Chen, X., Su, Y., Aydin, D., Bai, H., Jarimi, H., Zhang, X., Riffat, S. (2018). Experimental investigation of a polymer hollow fibre integrated liquid desiccant dehumidification system with aqueous potassium formate solution. Applied Thermal Engineering, 142: 632-643.

https://doi.org/10.1016/j.applthermaleng.2018.07.003

[28] Zheng, Z., Zhou, D., Gong, S. (2008). Studies of drying and sintering characteristics of gelcast $\mathrm{BaTiO}_{3}$-based ceramic parts. Ceramics International, 34(3): 551-555. https://doi.org/10.1016/j.ceramint.2006.12.001

[29] Rane, M.V., Reddy, S.V.K., Easow, R.R. (2005). Energy efficient liquid desiccant-based dryer. Applied Thermal Engineering, 25(5-6): 769-781. https://doi.org/10.1016/j.applthermaleng.2004.07.015

[30] Jeong, J., Yamaguchi, S., Saito, K., Kawai, S. (2011). Performance analysis of desiccant dehumidification 
systems driven by low-grade heat source. International Journal of Refrigeration, 34(4): 928-945. https://doi.org/10.1016/j.ijrefrig.2010.10.001

[31] Barati, A., Kokabi, M., Famili, N. (2003). Modeling of liquid desiccant drying method for gelcast ceramic parts. Ceramics International, 29(2): 199-207. https://doi.org/10.1016/S0272-8842(02)00106-2

[32] Barati, A., Kokabi, M., Famili, M.H.N. (2003). Drying of gelcast ceramic parts via the liquid desiccant method. Journal of the European Ceramic Society, 23(13): 22652272. https://doi.org/10.1016/S0955-2219(03)00045-1

[33] Dorouzi, M., Mortezapour, H., Akhavan, H.R., Moghaddam, A.G. (2018). Tomato slices drying in a liquid desiccant-assisted solar dryer coupled with a photovoltaic-thermal regeneration system. Solar Energy, 162:

364-371. https://doi.org/10.1016/j.solener.2018.01.025

[34] Naik, B.K., Joshi, M., Muthukumar, P., Sultan, M., Miyazaki, T., Shamshiri, R.R., Ashraf, H. (2020). Investigating solid and liquid desiccant dehumidification options for room air-conditioning and drying applications. Sustainability (Switzerland), 12(24): 1-22. https://doi.org/10.3390/su122410582

[35] Zhan, C., Yin, Y., Jin, X., Zhang, X. (2018). Effect analysis on performance and utilization of a novel compressed air drying system with a liquid desiccant cycle. $\quad$ Energy, 162: 60-71. https://doi.org/10.1016/j.energy.2018.07.183

[36] Lee, J.H., Ko, J.Y., Jeong, J.W. (2021). Design of heat pump-driven liquid desiccant air conditioning systems for residential building. Applied Thermal Engineering, 183(2):

116207. https://doi.org/10.1016/j.applthermaleng.2020.116207

[37] Habib, M.F., Ali, M., Sheikh, N.A., Badar, A.W., Mehmood, S. (2020). Building thermal load management through integration of solar assisted absorption and desiccant air conditioning systems: A model-based simulation-optimization approach. Journal of Building Engineering, 30:

101279 https://doi.org/10.1016/j.jobe.2020.101279

[38] Asadi, A., Meratizaman, M., Akbar, A. (2020). Feasibility study of small-scale gas engine integrated with innovative net-zero water desiccant cooling system and single-effect thermal desalination unit. International Journal of Refrigeration, 119: 276-293. https://doi.org/10.1016/j.ijrefrig.2020.06.025

[39] Fan, W., Kokogiannakis, G., Ma, Z. (2019). Integrative modelling and optimisation of a desiccant cooling system coupled with a photovoltaic thermal-solar air heater. Solar Energy, 193: 929-947. https://doi.org/10.1016/j.solener.2019.10.030

[40] Zhan, C., Yin, Y., Guo, X., Jin, X., Zhang, X. (2018). Investigation on drying performance and alternative analysis of different liquid desiccants in compressed air drying system. Energy, 165(B): 1-9. https://doi.org/10.1016/j.energy.2018.09.164

[41] Yin, Y., Zheng, B., Chen, T., Shao, B., Zhang, X. (2016). Investigation on coupled heat and mass transfer coefficients between compressed air and liquid desiccant in a packed dryer. International Journal of Heat and Mass
Transfer, 93:

$1218-1226$.

https://doi.org/10.1016/j.ijheatmasstransfer.2015.11.020

[42] Yin, Y., Zheng, B., Shao, B., Zhang, X. (2016). Experimental investigation on compressed air drying performance using pressurized liquid desiccant. Drying Technology, 34(3): 372-382. https://doi.org/10.1080/07373937.2015.1057838

[43] Singh, R.P., Mishra, V.K., Das, R.K. (2018). Desiccant materials for air conditioning applications - A review. IOP Conference Series: Materials Science and Engineering, $\quad 404(1)$ : 012005 . https://doi.org/10.1088/1757-899X/404/1/012005

\section{NOMENCLATURE}

$\begin{array}{ll}\text { mrr } & \text { maximum regeneration rate, } \mathrm{kg} / \mathrm{hr} \\ \text { RH } & \text { relative humidity, \% } \\ \text { RMSE } & \text { root mean square, \% } \\ \text { MAPE } & \text { mean absolute percentage error, \% } \\ \text { RPMs } & \text { revolutions per minutes, RPM } \\ \text { hd } & \text { mass transfer coefficient } \\ \text { hc } & \text { heat transfer coefficient }\end{array}$

\section{Subscripts}

\begin{tabular}{|c|c|}
\hline $\mathrm{LiCl}$ & lithium chloride \\
\hline $\mathrm{CaCl}_{2}$ & calcium chloride \\
\hline $\mathrm{LiBr}$ & lithium bromide \\
\hline EOF & electro-osmotic flow \\
\hline MRC & moisture removal capacity \\
\hline $\mathrm{COP}$ & coefficient of performance \\
\hline DC-HX & desiccant-coated heat exchanger \\
\hline DCHE & densely coating heat exchanger \\
\hline $\mathrm{COP}_{T H}$ & thermal coefficient of performance \\
\hline GPR & gaussian process regression \\
\hline SG & silica gel \\
\hline FF & fresh air \\
\hline FR & return/exhaust air \\
\hline SDCS & $\begin{array}{l}\text { solar-assisted hybrid solid desiccant cooling } \\
\text { system }\end{array}$ \\
\hline MRR & moisture removal rate \\
\hline ANN & artificial neural rate \\
\hline ANSYS & analysis of system \\
\hline LD & liquid desiccant \\
\hline PEG & polyethylene glycols \\
\hline DBD & desiccant-based dryer \\
\hline SECE & solar electricity to consume electricity \\
\hline SSDD & $\begin{array}{l}\text { single-stage solid } \quad \text { desiccant } \\
\text { dehumidification system }\end{array}$ \\
\hline TSDD & $\begin{array}{l}\text { two-stage solid desiccant dehumidification } \\
\text { system }\end{array}$ \\
\hline SLDD & $\begin{array}{l}\text { single-stage liquid } \\
\text { dehumidification system }\end{array}$ \\
\hline TLDD & $\begin{array}{l}\text { two-stage liquid desiccant dehumidification } \\
\text { system }\end{array}$ \\
\hline HPLD & heat pump-driven liquid desiccant \\
\hline IADS & integrated absorption desiccant system \\
\hline PVT-SAH & $\begin{array}{l}\text { photovoltaic-thermal collector-solar air } \\
\text { heater }\end{array}$ \\
\hline
\end{tabular}

